\title{
Phenotypic and genetic characterisation revealed the existence of several biotypes within the Neorautanenia brachypus (Harms) C.A. wild accessions in South East Lowveld, Zimbabwe
}

Trish. O. Nyarumbu' ${ }^{1}$ Tinotenda Kaseke ${ }^{2}$, Vimbai Gobvu ${ }^{3}$, Chrispen Murungweni ${ }^{3}$, Arnold. B. Mashingaidze ${ }^{4}$ and Zedias Chikwambi ${ }^{2^{*}}$ (1)

\begin{abstract}
Background: Local communities in the South Eastern Lowveld of Zimbabwe have adopted the feeding of livestock with Neorautanenia brachypus (Harms) C.A. tuber to mitigate against climate change. Differences within Neorautanenia brachypus (Harms) tuber flesh colour and preferences by cattle have been observed, suggesting possible diversity within the N. brachypus plant community. This study aimed at distinguishing the N. brachypus wild plant species through phenotypic and genetic characterization using morphological descriptors and random amplified polymorphic (RAPD) markers respectively. Leaf samples were selected using judgmental sampling techniques from wards 11-15 in Sengwe (Chiredzi district) for leaf morphology and molecular characterization. RAPD-PCR analysis was done using 18-screened random decamer primers to confirm the diversity in the plant population. The similarity of the biotypes was evaluated using binary coding on the basis of the presence or absence of a morphological indicator as well as distinct DNA amplicon fragments. Primer 7.0.13 was used to estimate morphological and genetic similarities using the unweighted pair group method with arithmetic average (UPGMA). The cluster number was estimated using the Elbow method part of the R package.
\end{abstract}

Results: Initially, 14 biotype groups were identified from 96 accessions visually characterized basing of leaf characteristics. All the leaf biotypes displayed arcuate venation with differences observed for leaf shape, tip shape and leaf margins. The 14 biotypes clustered into six groups based on the binary data of the morphological characteristics. RAPD primers generated three hundred and sixty eight distinct amplicons with $77.5 \%$ being polymorphic from the 14 biotypes. The number of bands produced per primer ranged from four (OPF-02) to 44 (UBC-746). The PIC value ranged from 0.1327 to 0.1873 for the RAPD primers. Use of molecular markers collapsed the biotypes into five clusters. Both the leaf descriptors and RAPD markers showed the existence of genetic diversity within the wild accessions of $N$. brachypus.

Conclusions: A combination of morphological and RAPD markers effectively refined the resolution of the genetic diversity within the N. brachypus wild accessions to nine biotypes. These findings have indicated to the existence of more than one biotype of $\mathrm{N}$. brachypus with potentially different properties. The favorable biotypes can further be

\footnotetext{
*Correspondence: zchikwambi@gmail.com

2 Department of Biotechnology, Chinhoyi University of Technology, P. Bag

7724, Chinhoyi, Zimbabwe

Full list of author information is available at the end of the article
}

(c) The Author(s) 2019. This article is distributed under the terms of the Creative Commons Attribution 4.0 International License (http://creativecommons.org/licenses/by/4.0/), which permits unrestricted use, distribution, and reproduction in any medium, provided you give appropriate credit to the original author(s) and the source, provide a link to the Creative Commons license, and indicate if changes were made. The Creative Commons Public Domain Dedication waiver (http://creativecommons.org/ publicdomain/zero/1.0/) applies to the data made available in this article, unless otherwise stated. 
promoted through incorporation in pastures as alternative feed or complementary feed to livestock. As such the output of this study will serve as a guide for N. brachypus germplasm management and improvement.

Keywords: Tuber, Random amplified polymorphic DNA (RAPD), Primer, Binary coding, Dendrogram, Genetic variability

\section{Background}

Recently, Neorautanenia brachypus (Harms) C.A. was identified in the South Eastern Lowveld of Zimbabwe as an important multipurpose legume tuber plant. The plant has been used as an alternative ruminant animal feed during periods of drought, wound remedy for livestock and a botanical pesticide against internal parasites in ruminants [1]. It belongs to the Leguminosae-Papilionaceae family. $N$. brachypus produces purple flowers, which forms dehiscent pods densely covered by hairs [2]. The chemical composition and nutritional values of the tubers reported by [1], indicated that the tubers can be used as a sole feed for cattle. Livestock play an important role in the household economies of families in arid regions of Zimbabwe [3, 4] and the worsening climatic conditions will be a huge challenge to livestock production. Farmers will be hard-pressed to ensure their livestock get enough nutrition especially through the harsh dry seasons. Most communities in this arid region are reported to be resource-challenged, thus the farmers struggle to buy in feed supplements and necessary commercial preventative and curative chemicals to fight disease [1]. Livestock would survive on the surrounding key browse plant species in the rangeland such as shrubs, tubers and noxious plants especially during severe dry periods [5]. However, some of the plants could be lethal to the animals. $N$. brachypus, like many other noxious plants, have bioactive properties that are awaiting proper understanding.

While $N$. brachypus exhibits a considerable variation in leaf shape, three distinct colour differences in flesh; white, light brown and dark brown (Additional file 1) were observed when preparing the tubers to feed the cattle (Zananwe-personal communication). The white tubers are soft and exude milky white substance and the brown tubers are more fibrous. Even though cattle feed on all tuber types of $N$. brachypus, cattle preferred the white tubers. Appropriate identification and characterization of plant materials is essential for their successful selections, domestication and conservation. Plants have many features that aid in their identification such as dimension, branch shape and area of development but one of the most defining features is their leaf [6]. The importance of leaf shape as a defining feature to distinguish species has been acknowledged by [7-10]. However, the effect of stage of development, environment and management practices have been cited as the major disadvantages for using morphological and biochemical markers [11].

Because morphological characteristics are considerably affected by the environmental factors [12], molecular markers provide an important tool for assessing the genetic variability and structure of natural populations [13]. The use of molecular techniques such as DNA barcoding, amplified fragment length polymorphism (AFLP), single nucleotide polymorphism (SNP) and random amplification of polymorphic DNA (RAPD) are increasingly being used in plant diversity studies $[14,15]$. Specifically RAPDs are increasingly being used because they are simple, quick and require no prior information of the sequence. RAPDs also provide markers that can be used to identify and discriminate genotypes, in addition to providing a means for assessing phenotypic expression and phylogenetic associations in the germplasm under study. RAPD analysis has been used extensively for genetic characterization of cassava plant accessions [16], the medicinal plant Bacopa monnieri [17], hibiscus, [18], African yam bean [11], Jacaranda decurrens Cham. [19] jatropha [20], sweet potato [21, 22], citrus [23] and apples [24]. However, some of the problems with RAPD are related to reproducibility, designing appropriate primers and amplification of RAPD-PCR products.

To our knowledge, nothing has been reported on the genetic diversity within $N$. brachypus wild plant accessions. Current use of the plant as a drought mitigation feed and for veterinary purposes is purely based on indigenous knowledge from the local communities. The objective of this study was to establish the diversity of $N$. brachypus wild plant species through phenotypic and genetic characterization using morphological descriptors and Random Amplified Polymorphic DNA (RAPD) markers.

\section{Methods \\ Investigation 1: Characterization of Neorautanenia brachypus based on leaf morphology Leaf sample collection}

A total of 100 leaf samples of $N$. brachypus were collected using judgmental sampling along a transect drive from wards 11-15 of Sengwe area, south of Gonarezhou National Park in Zimbabwe (Fig. 1). Judgmental or purposive sampling is a non-probability sampling technique where the researcher selects units to be sampled based 


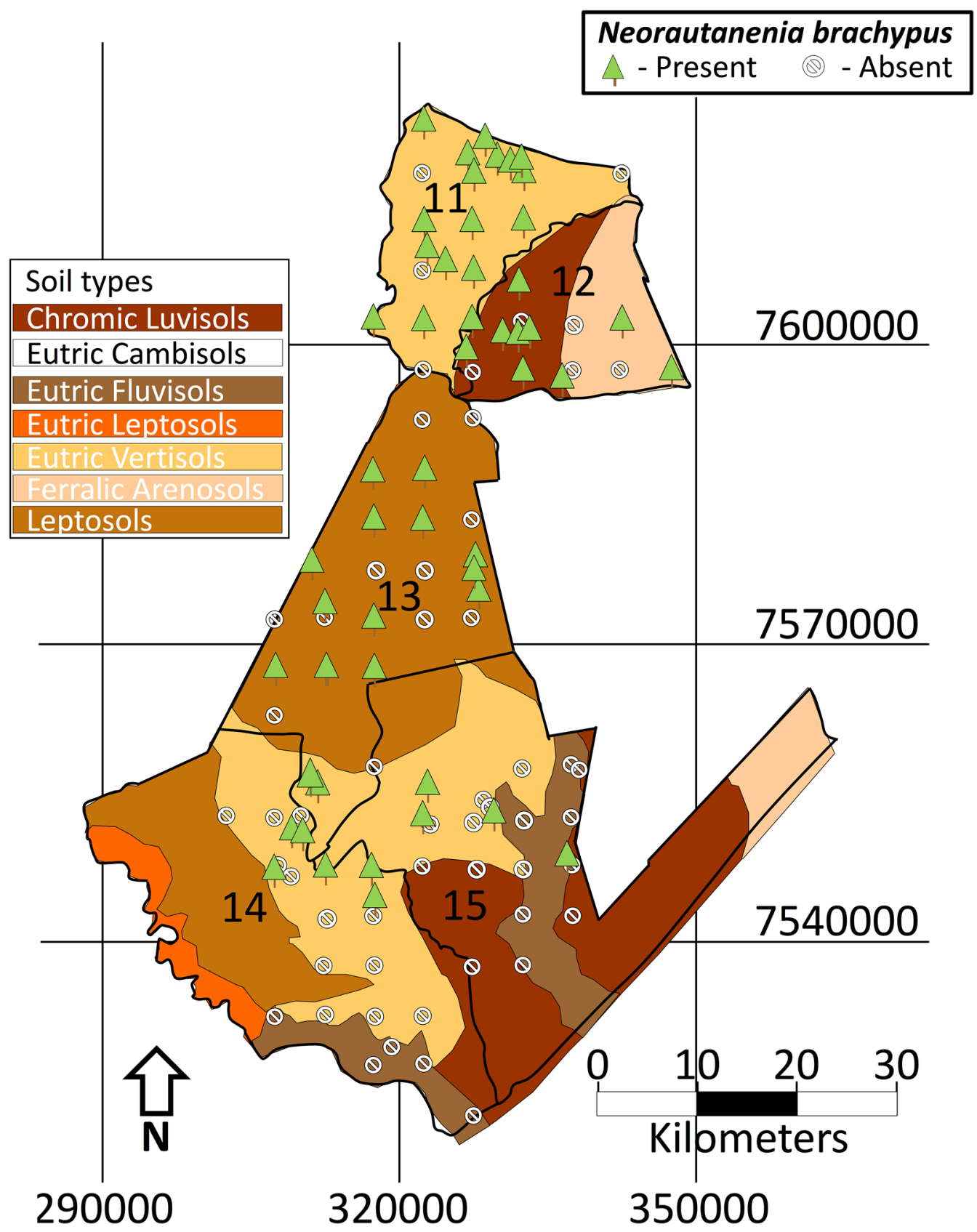

Fig. 1 Distribution of N. brachypus in relation to soil type in the South-East Lowveld of Zimbabwe (Adapted with permission from Murungweni et al. [1])

on their knowledge and professional judgment. The sampling technique is employed especially when the desired population is uncommon and difficult to locate. Samples were selected based on perceived visual differences on leaf shape and stem colour. Fully expanded and nonsenescent leaves were collected. The leaf samples were clearly labeled with (S) denoting the site from which the sample was collected and (PL) denoting the actual plant number sampled in the ascending order. Specific locations in terms of longitudinal and latitudinal coordinates were captured using a global positioning satellite system (Garmin eTrex 10). Additional information on the different soil type and surrounding vegetation was also collected. The leaf samples were classified based on leaf 
shape and maintained in a refrigerator at $-20{ }^{\circ} \mathrm{C}$ until they were used for DNA extraction.

\section{Classification of Neorautanenia brachypus based on leaf shape}

Morphological classification was done with respect to descriptors, leaf shape, leaf lobe type, leaf lobe numbers and shape of the central lobe according to [25] and tip shape, base shape and leaf margin [26]. The different features were recorded as binary data on the presence (one) or absence (zero) of features (Additional file 2). Photographs of the different leaf shapes were taken using a 16-megapixel digital camera for presentation.

A sample of 18 leaf biotypes was selected from the 96 accessions to represent the 14 visually clustered biotypes plus four whose leaves were not easily assigned to a group. From these 18, leaf shape was matched to their tuber pulp colour after cutting the tuber open. Pictures of leaf and the cut tubers were taken side by side. Classification was based on personal judgment basing on a tailor made sliding scale from one to six. The colour corresponded to the degree of whiteness of the tuber pulp and was scored one for more than $95 \%$ and for below $55 \%$. The colour bars correspond to the degree of whiteness of the tuber pulp.

\section{Statistical treatment of data}

The analysis of morphological data was done using hierarchical clustering, a method that is widely used for grouping data over a variety of scales. The binary data was analysed using the Primer 7.0.13. Cluster analysis was performed on the basis of the genetic similarity matrix and the resulting similarity co-efficients were used for constructing a dendrogram using the unweighted pair group method with arithmetic average (UPGMA. Presence or absence data for morphological visually accessible traits was used. The similarities between matrices were based on Jacquard's genetic similarity index. The selection of groups was based on number of clusters k-means using the Elbow method in the $\mathrm{R}$ package, where number of clusters is set at a level that explains most of the variability thus determining the threshold.

\section{Investigation 2: Classification of Neorautanenia brachypus based on RAPDs \\ Genomic DNA isolation from N. brachypus leaves}

Molecular markers further characterized the morphologically different leaf groups that were described by hierarchical clustering above. Molecular characterization was important to confirm that the biotypes were indeed different considering that genes are a more precise measure of plant composition. DNA was extracted from young $N$. brachypus leaves according to the ZR Plant/Seed DNA
MiniPrep ${ }^{\mathrm{TM}}$ kit protocol (Catalog No. D6020-Zymo Research Corp). DNA was eluted in $60 \mu \mathrm{l}$ of the DNA elution buffer. DNA quality was determined through gel electrophoresis in EZ-vision ${ }^{\circledR}$ (New England Bio labs) stained $1 \%$ agarose gel for sixty minutes at 100 volts in $1 \mathrm{X}$ Tris Borate EDTA (TBE).

\section{PCR amplification}

Forty three 10-mer random primers were sourced from Inqaba Biotechnology (Pty) Ltd South Africa. Primer selection was based on primers used in other RAPD marker studies for root and tuber crops ([11] and some randomly selected from Operon and the University of British Columbia pool [Operon Technologies, Alameda, Calif., USA) and University of British-Columbia, Canada (UBC primers)]. The lyophilized primers were reconstituted to a $10 \mu \mathrm{M}$ solution by adding Tris Edta buffer according to synthesis report (Inqaba biotec). PCR conditions were optimized considering the Tm $\mathrm{min} / \mathrm{max}$ of the different primers. The PCR reactions were conducted at a final volume of $25 \mu \mathrm{l}$, containing $5 \mu \mathrm{l}$ DNA template, $4 \mu \mathrm{l}$ primer $(10 \mu \mathrm{M}), 12.5 \mu \mathrm{l}$ master mix (One Taq $2 \mathrm{X}$ master mix with standard buffer) and $3.5 \mu \mathrm{l}$ nuclease free water. The PCR reaction was conducted using ARKTIK thermal cycler (Inqaba biotec). The thermal cycler was programmed for initial heat denaturation in one step of $1 \mathrm{~min}$ at $95^{\circ} \mathrm{C}$. Subsequent 45 cycles of denaturation for $1 \mathrm{~min}$ at $94{ }^{\circ} \mathrm{C}$; annealing at $34.5{ }^{\circ} \mathrm{C} / 36^{\circ} \mathrm{C}$ for $1 \mathrm{~min}$ and extension at $72{ }^{\circ} \mathrm{C}$ for one minute. Final extension was at $72{ }^{\circ} \mathrm{C}$ for $10 \mathrm{~min}$ then holding at $4{ }^{\circ} \mathrm{C}$ infinite. The annealing temperature differed for the two groups of primer sets based on their differences in melting temperatures. Finally $10 \mu \mathrm{l}$ of the PCR product was separated by gel electrophoresis in 1\% agarose gel stained by EZ-vision ${ }^{\circledR}$ in gel stain in $1 \mathrm{X}$ TBE buffer for $90 \mathrm{~min}$ at 100 volts. PCR amplicon banding patterns were visualized in a gel documentation system (Infinity Vilber Lourmat-Inqaba Biotech) under ultra violet light. Images of the gel were captured on the documentation system. A total of 18 primers were selected from the initial 43 after a screening and PCR optimization process. The primers were screened for their ability to amplify genes of morphologically different leaf groups of $N$. brachypus.

\section{RAPD scoring and data analysis}

The amplification products (bands) for each lane were scored using the Vision Capt program on the gel documentation system (Infinity Vilber Lourmat). The bands were scored according to their molecular weight. The sizes of produced DNA fragments were estimated by comparison with the standard molecular marker $1 \mathrm{~kb}$ and 100 bp DNA ladder (New England BioLabs). The biotypes were scored for presence or absence of a particular DNA 
Table 1 Leaf lamina shape variations among Neorautanenia brachypus leaf samples collected from five wards in Sengwe Chiredzi district, South-east Zimbabwe

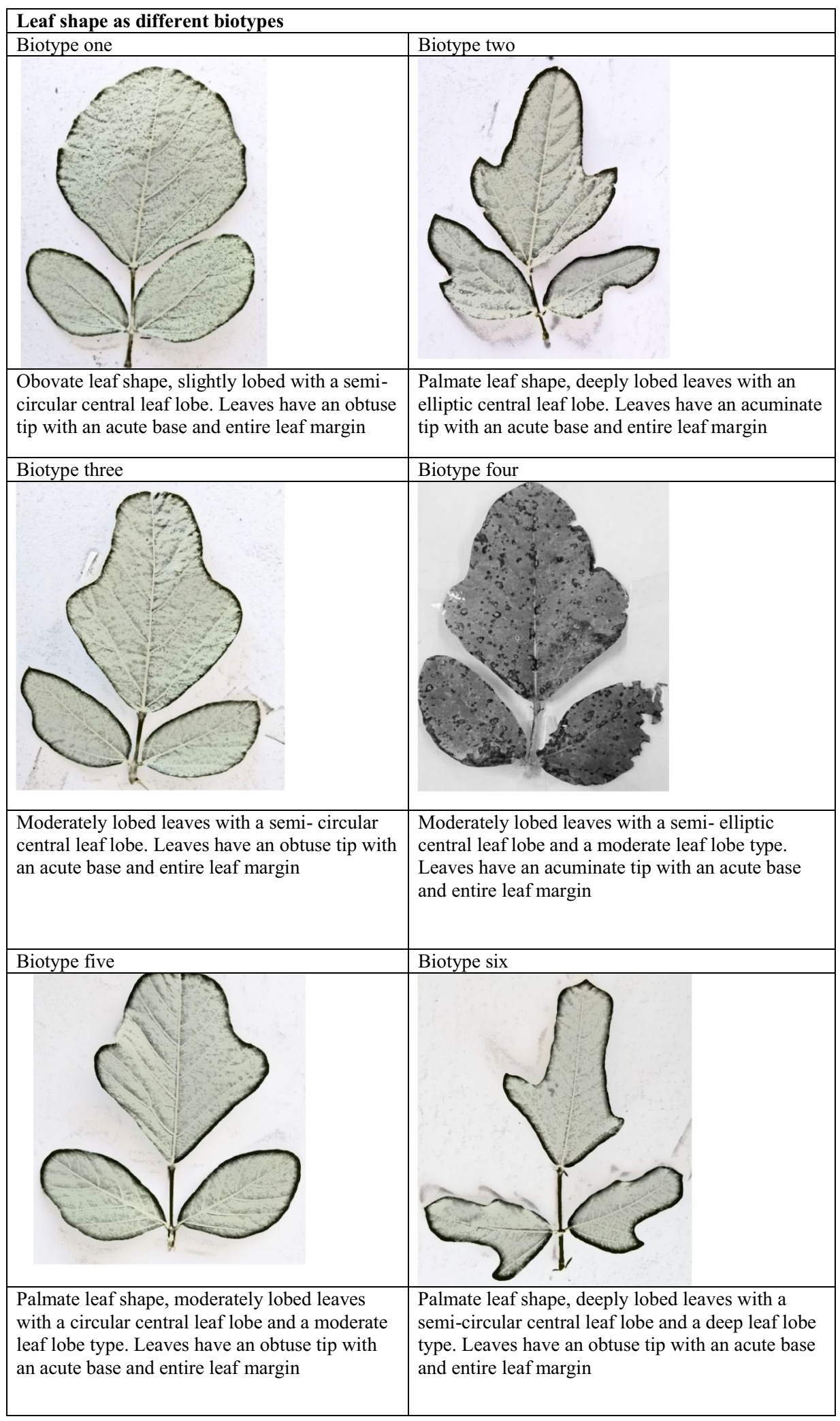


Table 1 (continued)

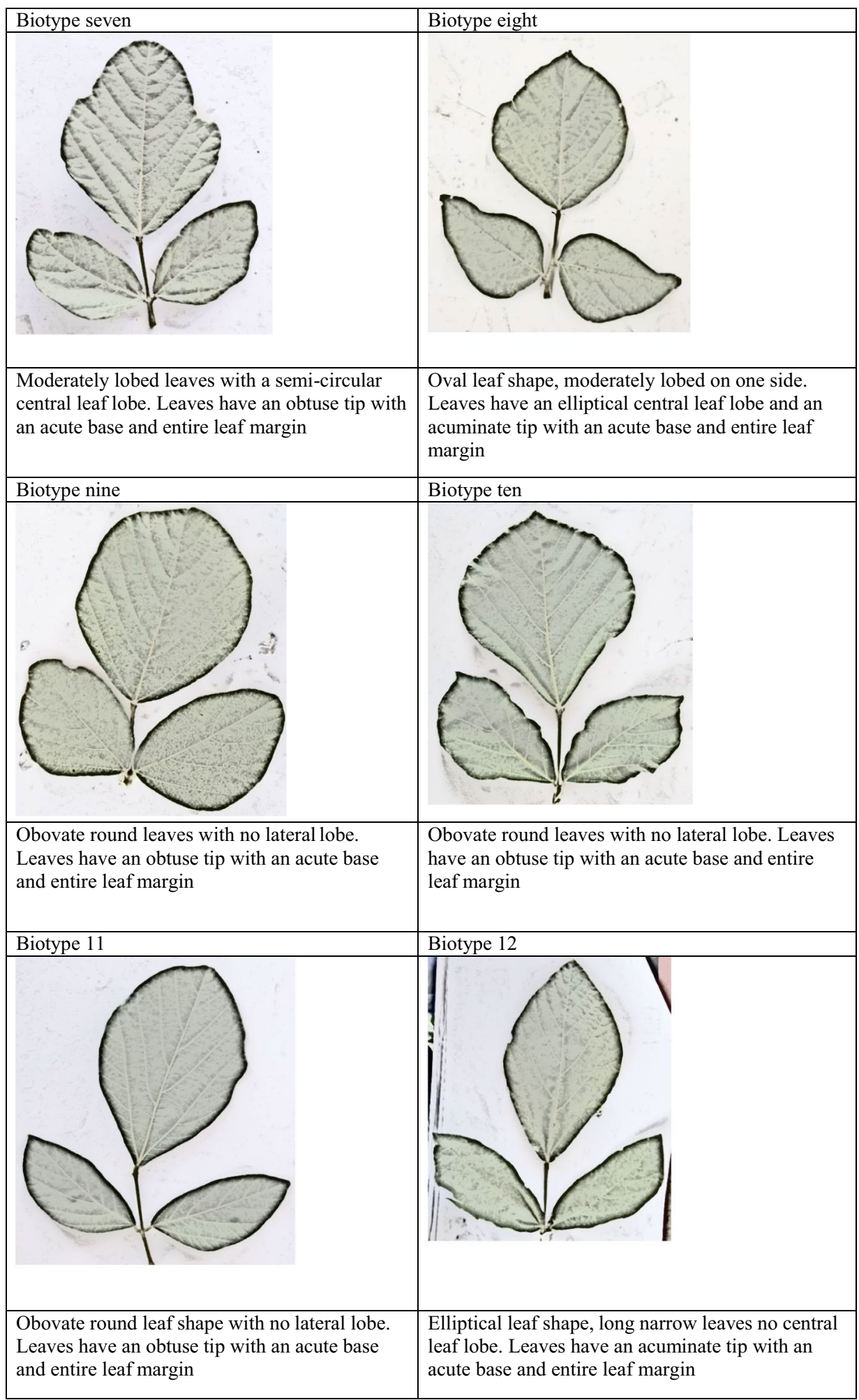


Table 1 (continued)

\begin{tabular}{|l|}
\hline Biotype 13 \\
\hline $\begin{array}{l}\text { Obovate leaf shape with no central leaf lobe. } \\
\text { Leaves have a cuspidate tip with an acute base } \\
\text { and entire leaf margin }\end{array}$
\end{tabular}

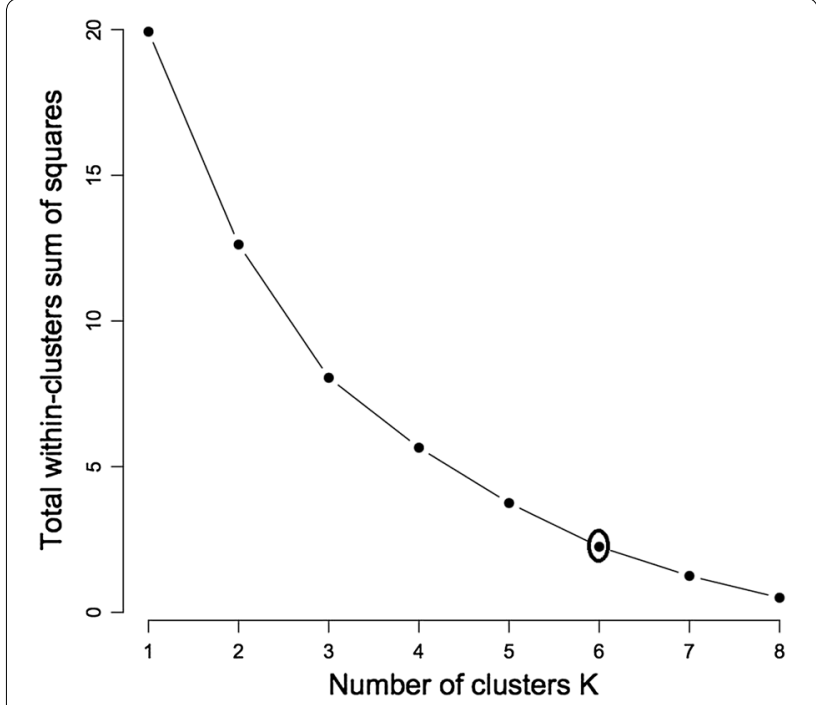

Fig. 2 Cluster optimisation curve based on leaf morphology classified by leaf length $(\mathrm{cm})$, width $(\mathrm{mm})$ and length to width ratio at $(K=6)$

fragment size as one or zero respectively. The binary data produced from scoring the amplicon-banding pattern of the RAPD PCR were used for estimating genetic similarity coefficients. Bands were identified either as monomorphic or polymorphic. Monomorphic bands are those which are present in all individuals and polymorphic are unique ones that are absent in at least one individual not in any other (Additional file 3). Cluster analysis was performed using Jaccard's genetic similarity index, and the resulting similarity co-efficient was used for constructing a dendrogram using the unweighted pair group method with arithmetic average (UPGMA) using Primer 7.0.13.

Polymorphic information content (PIC) values was calculated for each RAPD primer according to the formula:

$$
\mathrm{PIC}=1-\mathrm{R}(\mathrm{Pij}) 2,
$$

where $\mathrm{Pij}$ is the frequency of the ith pattern revealed by the jth primer summed across all patterns revealed by the primers [27].

\section{Results \\ Investigation 1: Characterization of Neorautanenia brachypus based on leaf morphology}

The findings from this study clearly show that there is some morphological diversity of leaves within the $N$. brachypus wild accession (Table 1). Initially, 14 morphological groups were identified by visual analysis of $N$. brachypus leaves. All the leaf samples displayed the arcuate venation with differences observed for leaf shape, tip shape and leaf margins. Biotype 12 constituted the largest proportion of leaf samples (27\%) and the least proportion of $0.1 \%$ was found in biotype eight (Additional file 4: Appendix S1). Cluster optimization was performed to define the level at which most data is retained with variability well explained. The optimum number of clusters was at $\mathrm{k}=6$ (Fig. 2). When cluster analysis was performed based on leaf morphology (leaf lengths, widths and the length to width ratios), six leaf groupings were formed (Fig. 3) at a threshold of 0.80 .

\section{Morphological descriptors used for separating N. brachypus plants by cluster analysis}

Leaf shape traits separated the 14 selected accessions, representing the 14 visually grouped clusters, into five biotypes; the ovate, obovate, elliptical/diamond and hastate. Ovate leaf types are broad below the middle and roughly $2 \times$ as long as it is wide and can be viewed as egg shaped. While obovate leaf types are broadest above the middle and roughly $2 \times$ as long as it is wide (leaf shows 


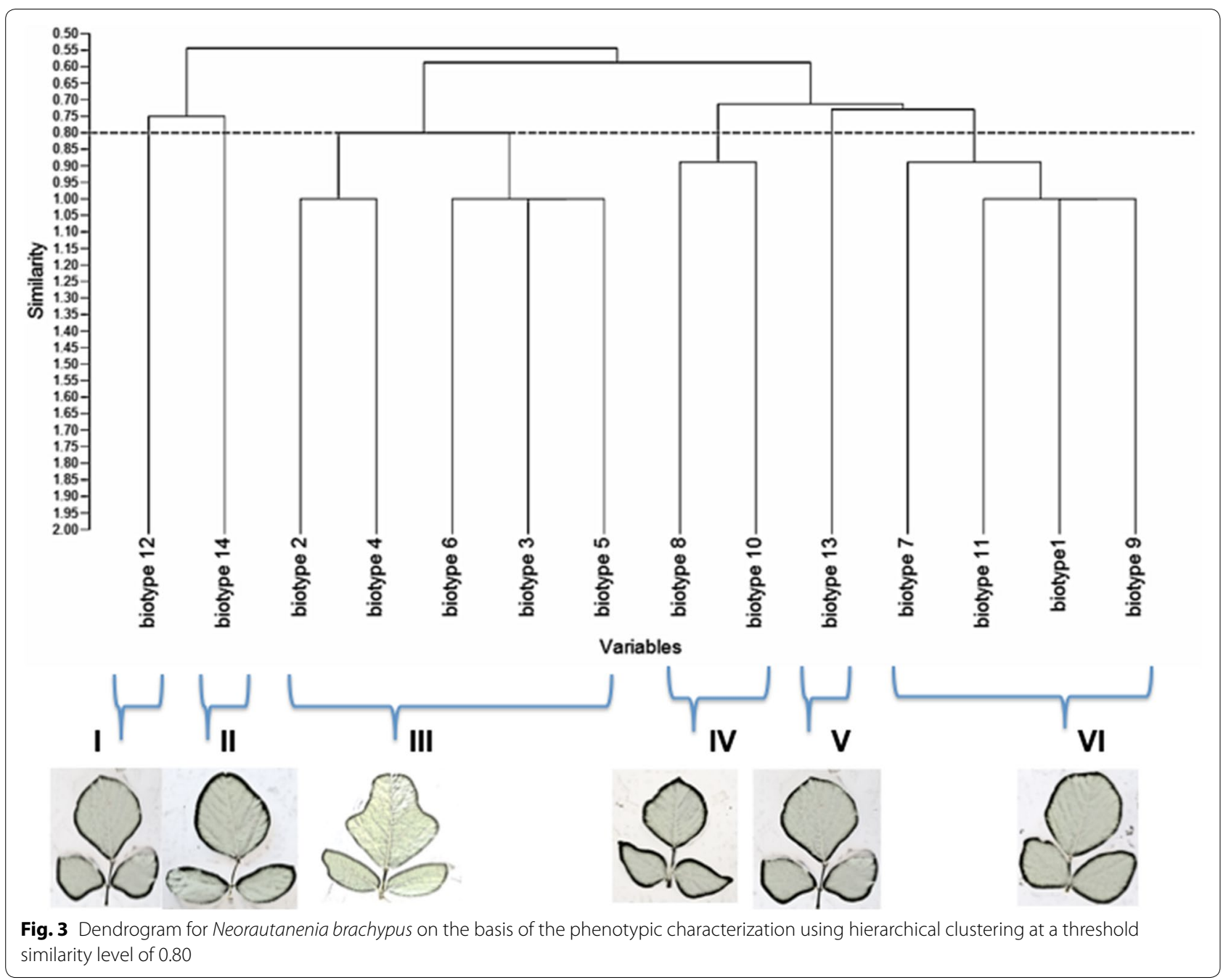

the reverse of ovate). Triangular leaves with basal lobes are classified as hastate. Elliptical or diamond are leaves that had the broadest width in the middle and then taper off at the ends.

Leaf blade edge/margins was separated into three types; entire, lobate and undulate. Entire leaf edges are even and smooth throughout while lobate leaf edges are indented and undulate edges are wavy. Leaf veins are classified as arcuate where veins emerge from the central vein/mid rib in a sort of arc shape.

Tip shape was separated into three types; acuminate, cuspidate and obtuse. Acuminate tip shape are leaf blades with rounded shoulders leading to a pointed tip; cuspidate are leaf tip forming a short, narrow point. Obtuse leaves are narrow with a rounded tip.

The results show that there is some relationship between $N$. brachypus flesh colour and leaf shape (Fig. 4). It was observed that all 18 the leaf samples biotypes selected had more than $50 \%$ degree of whitening. The colour observation tended to cluster the lobed leaves together as shown by (c) and (d) groups.

\section{Investigation 2: Classification of Neorautanenia brachypus based on RAPDS}

The results from the study shows that the primers produced polymorphic RAPD fragment patterns. Figure 5 shows typical example of DNA polymorphism as detected for the Operon primers UBC 740 (a) and UBC 738 (b) respectively.

The selected 18 primers produced a total of 368 bands for the 14 biotypes with $77.5 \%$ of the genes showing polymorphism (Table 2). The number of bands produced per primer ranged from four (OPF-02) and 44 (UBC-746). The average number of bands per primer was 17.52 while average number of polymorphic bands was 13.95. The primer OPAD-9 gave the lowest percentage 


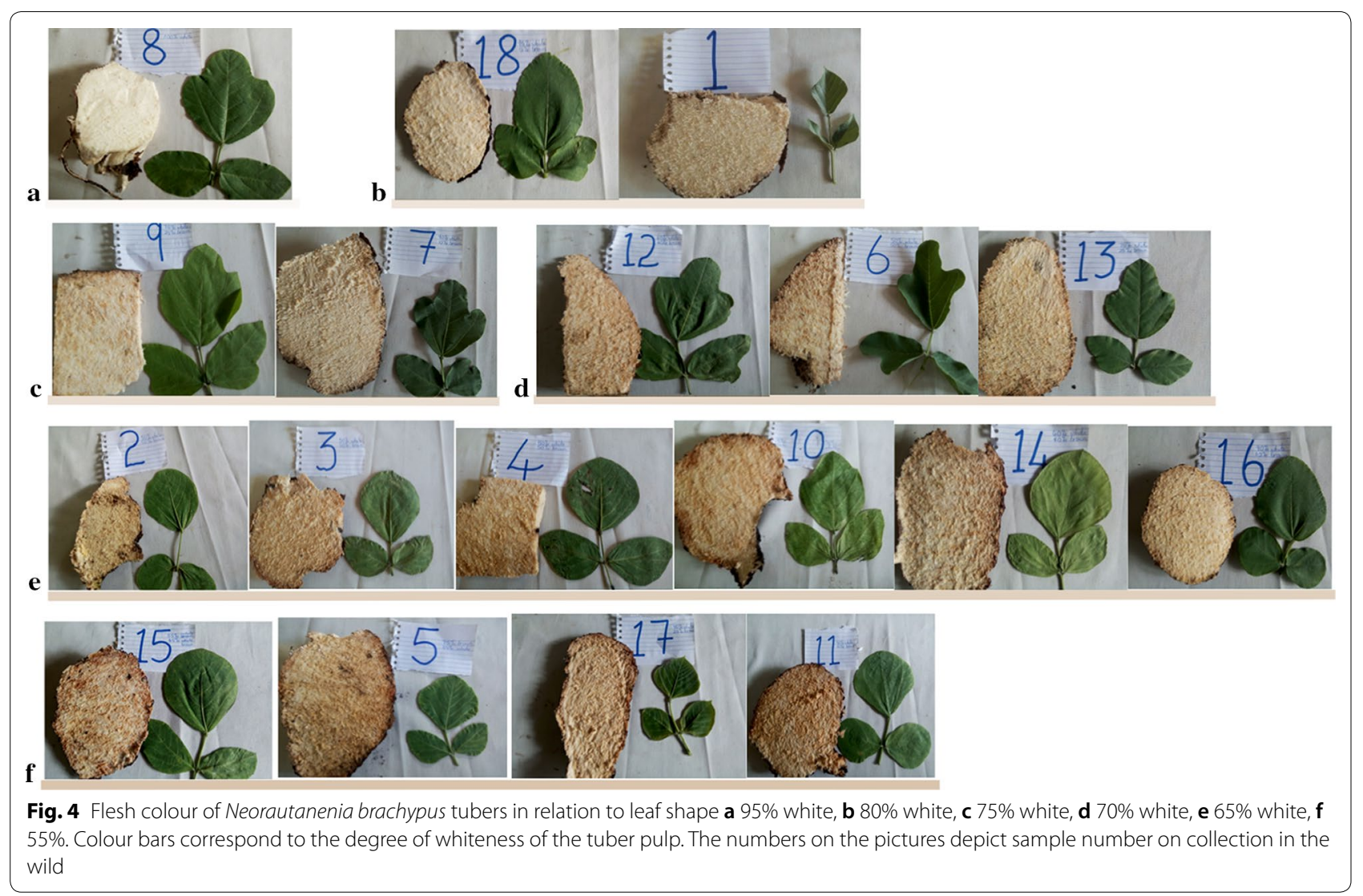

$\mathbf{a}$

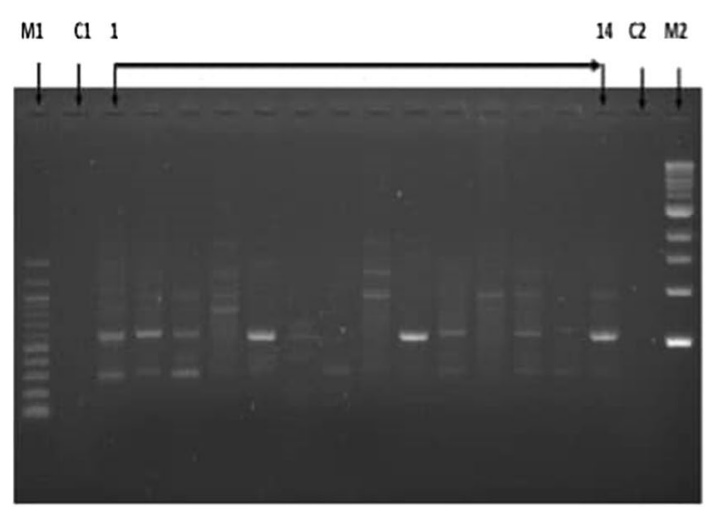

b

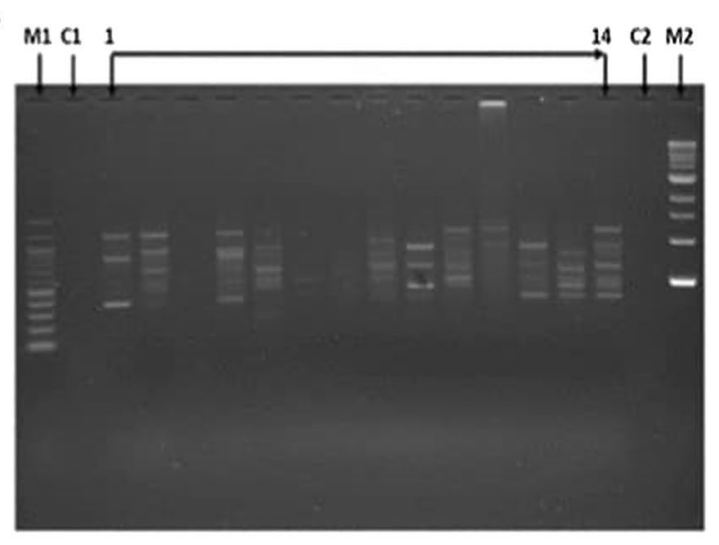

Fig. 5 Profiles for RAPD bands obtained with the primers UBC 740 (a) and UBC 738 (b) for Neorautanenia brachypus wild accessions: M1 and M2 are $100 \mathrm{bp}$ and $1 \mathrm{~kb}$ DNA markers respectively, C1 and C2 is the control. 1-14 indicate biotypes 1 to 14 as described in Table 1

of polymorphism (16.7) while primers OPAB-17, OPAL -11 , OPN-11 and UBC- 745 gave the highest percentage of polymorphism (100). The range of PIC values of the primers were 0.1327 (OPE-03) to 0.1873 (OPL-03) with an average of 0.157 (Table 2).

The cluster optimization was performed and was fit at $k=5$ (Fig. 6). The dendrogram based on RAPD primers placed the 14 biotypes into five distinct clusters, I, II, III, IV and V (Fig. 7) with cluster grouping determined at threshold 0.05. Leaves in cluster I had a common feature of being lobed except biotype 1 as previously explained by leaf morphology. Cluster II had their leaf tip shape, base shape and entire margin in common except biotype 13. The third cluster had nothing in common. The fourth 
Table 2 Sequence of 18 RAPD-PCR primers, total number of scored bands, number of polymorphic bands, percentage polymorphism and polymorphic information content of Neorautanenia brachypus leaf samples

\begin{tabular}{|c|c|c|c|c|c|}
\hline Primer & Primer sequence $5^{\prime} 3^{\prime}$ & $\begin{array}{l}\text { Total number } \\
\text { of bands }\end{array}$ & $\begin{array}{l}\text { Number } \\
\text { of polymorphic bands }\end{array}$ & $\begin{array}{l}\text { Percentage } \\
\text { polymorphism }\end{array}$ & $\begin{array}{l}\text { Polymorphic } \\
\text { information content } \\
\text { (PIC) }\end{array}$ \\
\hline OPE-03 & CCAGATGCAC & 8 & 6 & 75.00 & 0.1327 \\
\hline OPL-03 & CCAGCAGCTT & 21 & 18 & 85.71 & 0.1873 \\
\hline OPAS-14 & TCGCAGCGTT & 6 & 4 & 66.67 & 0.1429 \\
\hline OPAB-17 & TCGCATCCAG & 11 & 11 & 100.00 & 0.1748 \\
\hline OPN-11 & TCGCCGCAAA & 8 & 8 & 100.00 & 0.1451 \\
\hline OPAL-14 & TCGCTCCGTT & 11 & 11 & 100.00 & 0.1497 \\
\hline UBC-434 & TCGCTAGTCC & 11 & 10 & 90.91 & 0.1439 \\
\hline UBC-737 & GGTGGGTGTG & 29 & 26 & 89.66 & 0.1534 \\
\hline UBC-738 & GGTGGGTGGT & 40 & 34 & 85.00 & 0.1747 \\
\hline UBC-742 & ССТСССТССТ & 11 & 10 & 90.91 & 0.1327 \\
\hline UBC-743 & CCACCCCAC & 24 & 13 & 54.17 & 0.1622 \\
\hline UBC-744 & CCACCCACCA & 13 & 12 & 92.31 & 0.1439 \\
\hline UBC-745 & GGGAAGAGGG & 14 & 14 & 100.00 & 0.1514 \\
\hline UBC-746 & GGGTGTTGGG & 44 & 37 & 84.09 & 0.1487 \\
\hline UBC-740 & GGAGGGAGGA & 28 & 18 & 64.29 & 0.1851 \\
\hline OPAY-10 & CAAGGCCCCT & 22 & 14 & 63.64 & 0.1681 \\
\hline OPAY-11 & ACGCGCCTTC & 29 & 22 & 75.86 & 0.1727 \\
\hline OPAY-12 & CTGTCGGCGT & 21 & 18 & 85.71 & 0.1577 \\
\hline Total & & 368 & 293 & - & \\
\hline Average & & 17.52 & 13.95 & 77.51 & 0.157 \\
\hline
\end{tabular}

and fifth clusters were outliers, thus two independent groups constituting one biotype each.

A combination of both morphological and molecular characterizatics placed the biotypes into nine distinct

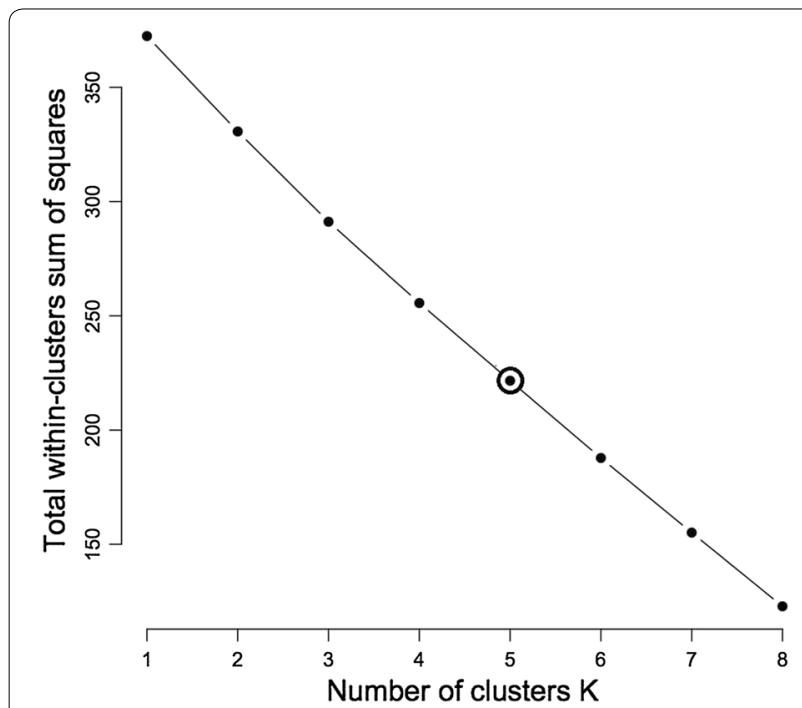

Fig. 6 Cluster optimisation curve for Neorautanenia brachypus biotypes classified using RAPDs at best fit $(k=5)$ clusters (Fig. 8) after cluster optimization at $\mathrm{k}=9$ (Fig. 9). The combination maintained biotypes 2 and 6 and biotypes 3 and 5 as in morphology clustering.

\section{Discussion}

This is the first study to use plant morphological characteristics and RAPD molecular markers to examine the genetic variability of $N$. brachypus wild population. The findings from this study show that there is both morphological and genetic diversity within the $N$. brachypus wild accession. Both the morphological and genetic differences substantiate observations by local farmers on tuber colour, quality and animal preferences as pointed out by Zanamwe (personal communications). However, some distinct variations noticeable by leaf shape could not be verified through molecular work as they were placed in different clusters by RAPDs. This confirms arguments by [28], who pointed out that, in general, the association of genetic variation with environmental conditions can be limited by natural selection and local gene dispersal. However, studies by [29] indicate that land use types significantly influences the structural and compositional attributes of vegetation. This finding supports work by [1] who identified that $N$. brachypus is widely distributed in cultivated fields. 


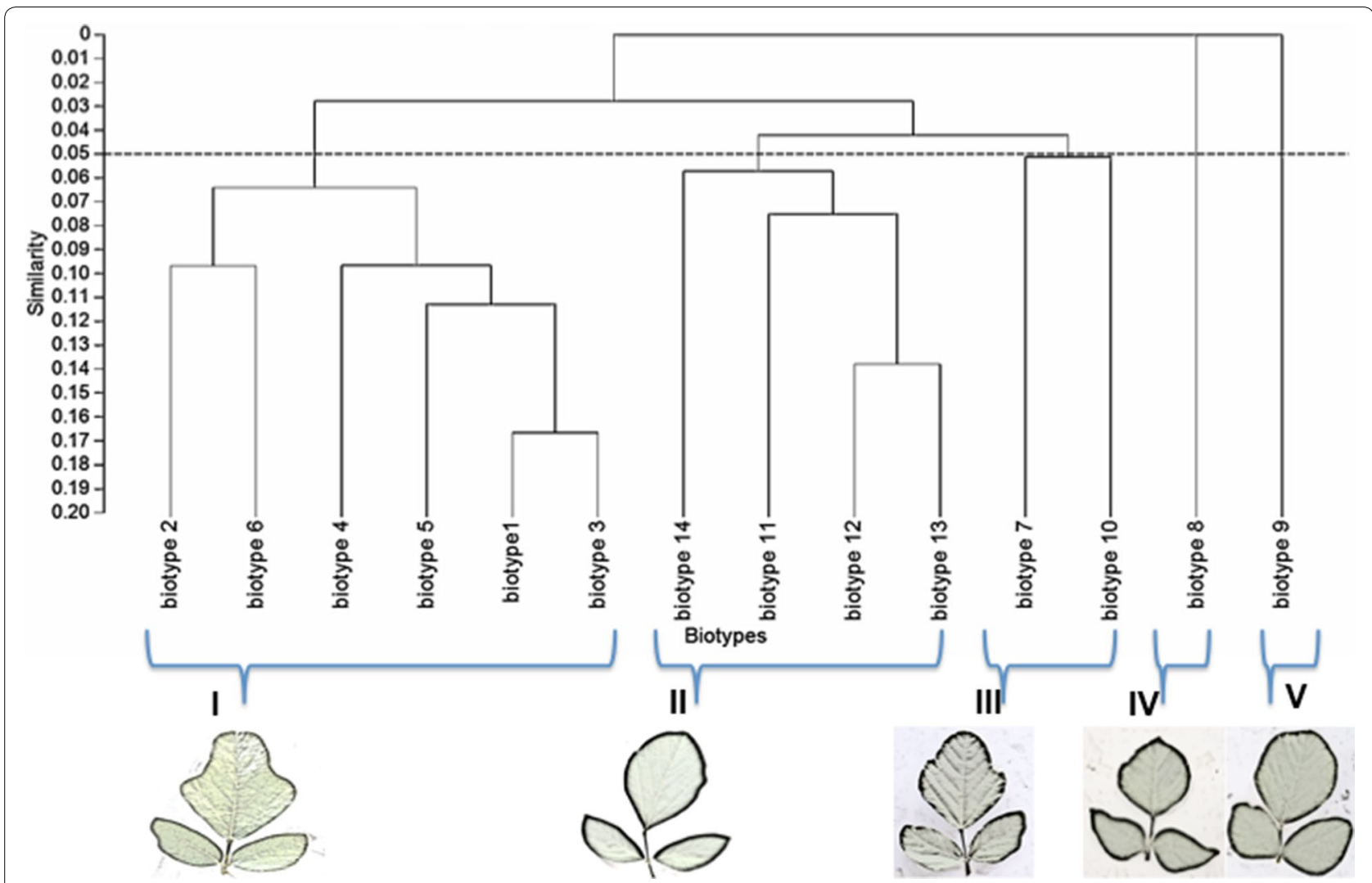

Fig. 7 Dendrogram for Neorautanenia brachypus on the basis of combined RAPD profiles using hierarchical clustering at a threshold similarity distance level of 0.05

Since leaves carry out photosynthesis that is important to plant growth and survival, variation in their shape could reflect natural selection for their function. A number of theories proposed to explain leaf diversity include thermoregulation of leaves mostly in arid and hot environments, hydraulic constraints, patterns of leaf expansion, biomechanical constraints, adaptations to avoid herbivory and adaptations to optimise light interception [30]. The variation in $N$. brachypus leaves could explain its adaptation to the semi-arid dry region of Zimbabwe. Being an angiospermous plant, $N$. brachypus also reflects random variation within the context of its phylogenetic history [31]. The leaf morphological variations across the biotypes are testimony to the importance of the leaf organ as an adaptive structure [32]. The lack of a defined relationship between leaf shape and tuber flesh colour can be better explained by its genetic makeup, location of growing and year of growing and or time of harvesting as described by [33, 34] in Irish potatoes. The study identified that the presence of carotenoids and anthocyanins positively influences tuber flesh colour.

However, due to these restrictions in morphological variability, [17] cited that molecular tools provide valuable data on diversity through their ability to detect variation at the DNA level. High genetic diversity among fruits has been reported; [23] on citrus and [24] on apples using plant morphology and RAPD markers. In this study RAPD primers were also able to detect some genetic diversity among $N$. brachypus wild accessions. The PIC values for 18 primers were on average 0.157 indicating their high discriminatory power. This PIC value is much lower than the maximum value given by [35] of 0.5 for dominant markers.

The combination of phenotypic characterization and RAPDs increased the resolution of identifying diversity as shown by the higher cophenetic correlation coefficient of 0.9316 and a cluster number of 9 . However, there were some discrepancies existing between the morphological indicators and molecular indicators. Interestingly, morphological classification placed biotype two and biotype six in different groups but they were placed in one cluster with RAPDs. These discrepancies may be related to genotypes and the selection of RAPD primers. 


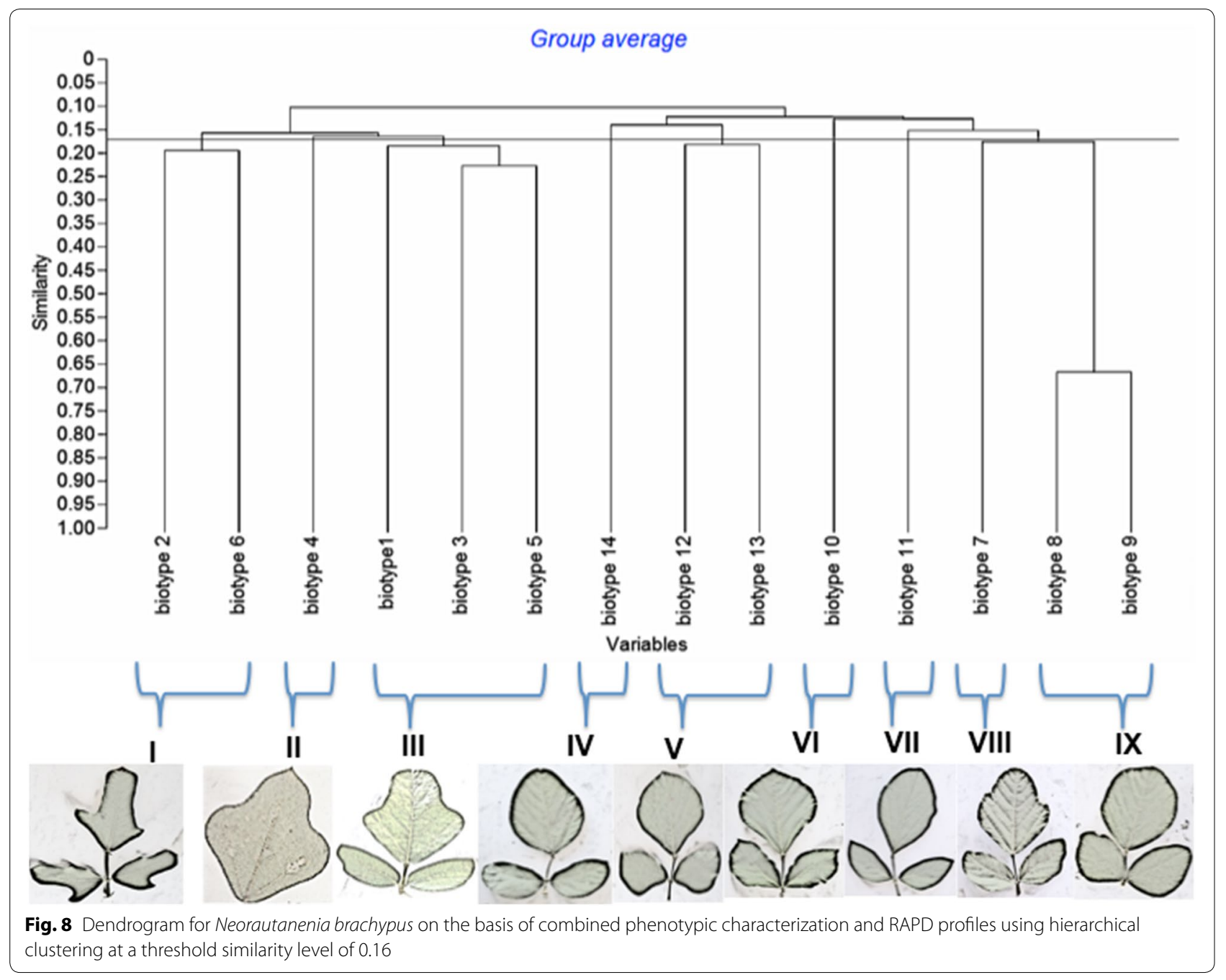

This lack of correlation between morphological traits and molecular markers could be explained by several factors as cited by [36]. The selected primers could not have covered vast area of $N$. brachypus genome or morphological variation could have been strongly influenced by environmental conditions or maybe the morphological similarities observed might be due to different combinations of alleles producing similar phenotypes. Cluster analysis with RAPDs narrowed down biotype groupings from ten to five. Different clustering of genotypes using plant morphology and RAPD polymorphism were previously reported from [24] on citrus, [17] on the medicinal plant Bacopa monnieri (L.) and [19] on Jacaranda decurrens Cham. This justifies arguments by [11] that morphological characters may not be obvious at all stages of plant development and appearance may be affected by environment.

\section{Conclusions}

Findings of the present study reveal that $N$. brachypus germplasm presented some high diversity based on both phenotypic and RAPD-PCR assessment approaches. However, the results of both techniques are slightly different in comparison of their efficiency. The variability shows that RAPD markers are an ideal technique as they give more accurate assessments with a high level of precision as compared to plant morphology. However, it can be concluded that the techniques are more effective when used in combination since molecular work generally follows morphological characterisation. On the basis of results of this study, future studies on genetic diversity, using other molecular markers is possible for higher genetic resolution of the genome. The results of this study may be useful in establishing domestication and conservation strategies 


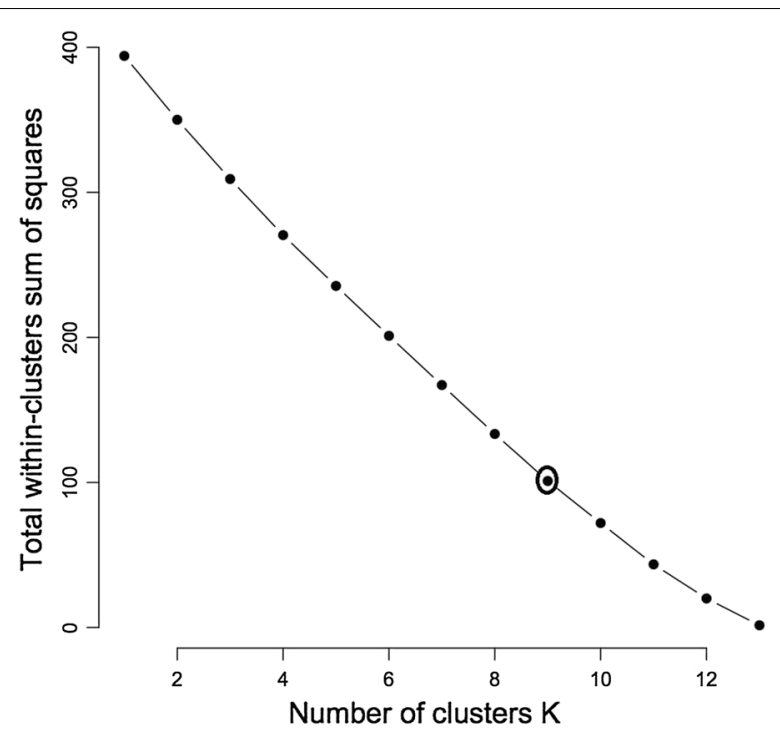

Fig. 9 Cluster optimisation curve for Neorautanenia brachypus biotypes on the basis of combined phenotypic characterization and RAPD profiles at threshold $(k=9)$ of $N$. brachypus in Zimbabwe. We are therefore recommending that selected biotypes be grown and monitored on their growth and developmental stages to ascertain their effects on the tuber colour and possibly composition, which is of preference to livestock.

\section{Additional files}

Additional file 1. Neorautanenia brachypus tuber flesh colors. The file shows the main tuber flesh colors of sampled Neorautanenia brachypus. Three colour differences noted when tubers were cut across are white flesh, light brown flesh and dark brown flesh. Tubers of approximately same size were used as samples.

Additional file 2. Leaf morphological attributes scored. The file shows the measured as well as the scored leaf attributes of the descriptors for each sampled Neorautanenia brachypus plant accession. The columns are the descriptors while the rows are the plant accessions. Measurement and scoring of descriptors was done according to [22] and [23].

Additional file 3. Binary data presentation of the RAPD Polymorphic DNA fragments for the 14 morphologically distinguished biotypes. The file shows the binary score of each polymorphic DNA fragment produced by the RAPD banding pattern. The columns are the biotypes while the rows are the RAPD primers; indicating primer name and polymorphic DNA fragment size. The fragments are scored for each biotype as presence or absent; one and zero respectively.

Additional file 4: Appendix S1. GPS data from leaf collection sites. The file shows the geographical positions from which the Neorautanenia brachypus plants were collected. The coordinates shows the exact sites were plant specimens were collected in the South Eastern Lowveld of Zimbabwe. The selected sites were based on previous work by [4].

\section{Abbreviations}

RAPD: Random Amplification of Polymorphic DNA; UPGMA: unweighted pair group method with arithmetic average; AFLP: amplified fragment length polymorphism; SNP: single nucleotide polymorphism; CP: cophenetic correlation coefficient; PIC: polymorphic information content.

\section{Authors' contributions}

ZC-Designed and supervised the experiment, corrected the manuscript; TON_Expanded the morphological data collection protocols, collected data in field and laboratory, analyzed results; TBK — Carried out RAPD analysis of the Zhombwe biotypes; VG_Collected morphological data of the Zhombwe biotypes; CM and ABM-Designed the infield experimental layout and analysed the results in the contest of the known application and distribution of Zhombwe. All authors read and approved the final manuscript.

\section{Author details}

${ }^{1}$ Horticulture Research Institute, P.O. Box 810, Marondera, Zimbabwe.

2 Department of Biotechnology, Chinhoyi University of Technology, P. Bag 7724, Chinhoyi, Zimbabwe. ${ }^{3}$ Department of Animal Production and Technology, Chinhoyi University of Technology, P. Bag 7724, Chinhoyi, Zimbabwe. ${ }^{4}$ Department of Crop Science and Post-Harvest Technology, Chinhoyi University of Technology, P. Bag 7724, Chinhoyi, Zimbabwe.

\section{Acknowledgements}

Gratitude is extended to Chinhoyi University of Technology, the Department of Agricultural Technology and the Department of Biotechnology for availing the resources required for experiments and access to laboratory space. The effort of each Zhombwe research team member is greatly appreciated in demystifying the ecology and functions of Zhombwe.

\section{Competing interests}

The authors declare that they have no competing interests.

\section{Availability of data and materials}

Plant material used is available at the designated geographical locations (Additional file 4: Appendix S1) and upon request from the corresponding author.

\section{Consent for publication}

Not applicable.

\section{Ethics approval and consent to participate}

The plant materials (seeds and leaves) were collected in the wild and farmers' fields following institutional and national guidelines. There is no specimen for this plant in our national herbarium.

\section{Funding}

The study was wholly funded by Chinhoyi University of Technology Vice Chancellor scholarship and Zhombwe (N. brachypus) research funds. The funds covered all the travelling costs to the field for specimen collection and laboratory work.

\section{Publisher's Note}

Springer Nature remains neutral with regard to jurisdictional claims in published maps and institutional affiliations.

Received: 19 December 2017 Accepted: 28 February 2019

Published online: 12 March 2019

\section{References}

1. Murungweni C, Andersson J, Van Wijk M, Gwitira I, Giller K. Zhombwe (Neorautanenia brachypus (Harms) CA Sm.) - a recent discovery for mitigating effects of drought on livestock in semi-arid areas of Southern Africa. Ethnobot Res Appl. 2012;10:199-212.

2. Hyde M, Wursten B, Ballings P, Dondenye S, Palgrace C. Flora of Mozambique: species information: Neorautanenia brachypus. 2014; 2014. http://www.mozambiqueflora.com/speciesdata/species.php?speci es_id $=131370$. Accessed 4 Oct 2014.

3. Murungweni C, van Wijk M, Giller K, Andersson J, Smaling EM. Adaptive livelihood strategies employed by farmers to close the food gap in semiarid south eastern Zimbabwe. Food Secur. 2014;6:313-26. 
4. Cumming DHM. Wildlife, Livestock and food security in the South East Lowveld of Zimbabwe. In: Osofsky SA, Cleaveland S, Karesh WB, Kock MD, Nyhus PJ, Starr L, Yang A, editors. Conservation and development interventions at the wildlife/livestockinterface: implications for wildlife, livestock, and human health. Gland: IUCN; 2005. p. 41-6.

5. Mudzengi CP, Murwira A, Zengeya FM, Murungweni C. Screening key browse species in a semi-arid rangeland. Cogent Food Agric. 2017;31:1285854.

6. Dragos C. Mobile Plant Classification. Diploma thesis. Karlsruhe Institute of Technology; 2012. https://fipa.cs.kit.edu/download/thesis/ da-constantin.pdf.

7. Tsukaya H. Mechanism of leaf shape fetermonation. Annu Rev Plant Biol. 2006;57:477-96.

8. Belhumeur P, Chen D, Feiner S, Jacobs D, Kress J, Ling H, et al. Searching the Worlds herbaria: a system for visual identification of plant species. In: European conference on computer vision. ECCV; 2008. p. 116-29.

9. Yanikoglu B, Aptoula E, Tirkaz C. Sabanci-Okan systemat ImageClef 2011: Plant identfication task. In: Petras P, Clough P, editors. CLEF Notebook (Papers/Labs/Workshop). 2011.

10. SoMouine S, Yahiaoui I, Verroust-Blondet A. Plant species recognition using spartial correlation between the leaf margin and leaf salient points. In: IEEE international conference on image processing. Melbourne, Australia; 2013.

11. Moyib OK, Gbadegesin MA, Aina OO, Odunola O. Genetic variation within a collection of Nigerian accessions of African Yam Bean (Sphenostylis stenocarpa) revealed by RAPD primers. Afr J Biotechnol. 2008:7:1839-46.

12. Ikbal K, Boora S, Dhillon R. Evaluation of Jatropha curacs L. using RAPD markers. Ind J Biotechnol. 2010;9:50-7.

13. Frankham R, Ballou J, Brioscoe D. Introduction to conservation genetics. Cambridge: Cambridge University Press; 2002

14. Govindaraj M, Vetriventhan M, Srinivasan M. Review article importance of genetic diversity assessment in crop plants and its recent advances: an overview of its analytical perspectives. Genet Res Int. 2015;2015:1-14. https://doi.org/10.1155/2015/431487.

15. Fu YB. Understanding crop genetic diversity under modern plant breeding. Theor Appl Genet. 2015;128:2131-42.

16. Tonukari N, Thottapilly G, Ng N, Mignouna H. Genetic polymorphism of cassava within the Republic of Benin detected with RAPD markers. Afr J Crop Sci. 1997:5:219-28

17. Tripathi N, Chouhan NS, Saini N, Tiwari S. Assessment of genetic variations among highly endangered medicinal plant Bacopa monnieri (L.) from central India using RAPD and ISSR analysis. Biotechnology. 2012;2:327-36.

18. Prasad M. Molecular characterization and genetic diversity determination of Hibiscus species using RAPD molecular markers. Asian J Plant Sci. 2014:4:50-6.

19. Bertoni BW, Telles MP, Malosso MG, Torres SC, Pereira JO, Lourenco M, et al. Genetic diversity in natural populations of Jacaranda decurrens Cham. Determined usinng RAPD and AFLP markers. Genet Mol Biol. 2010;33:532-8.

20. Chen K, Ren P, Ying C, Jiang Q, Jia X. Genetic relationships among of Jatropha curcas L. clones from Panzhihua, China as revealed by RAPD and ISSR. Afr J Agric Res. 2011;6:2582-5.
21. de Andrade EKV, de Andrade júnior VC, de Laia ML, Fernandes JSC, Oliveira AJM, Azevedo AM, et al. Genetic dissimilarity among sweet potato genotypes using morphological and molecular descriptors. Acta Sci Agron. 2017;39:447. https://doi.org/10.4025/actasciagron.v39i4.32847.

22. Gichuki S, Berenyi M, Zhang D, Hermann M, Schmidt J, Glossl J, et al. Genetc diversity in sweetpotato (Ipomea batatas (L.) Lam) in relationship to geographic sources as assesses with RAPD markers. Genet Evol. 2003;50:429-37.

23. Sayed LM, Mahmoud MF. Moleculer characterisation and genetic diversity of some Egyptian citrus cultivars using RAPD and ISSR markers. Egypt J Genet Cytol. 2016;44:387-403.

24. Zarei A, Erfani-Moghadam J, Mozaffari M. Phylogenetic analysis among some pome fruit trees of Rosaceae family using RAPD markers. Biotechnol Biotechnol Equip. 2017;31:289-98. https://doi.org/10.1080/13102 818.2016.1276414.

25. Huaman Z. Discriptors for sweetpotato. Rome: International Board for Plant Genetic Resources; 1991.

26. Whiting D, McMulkin L, Jones J, O'Connor A, Pott L. Identifying broadleaf flowering trees and shrubs. Identifying broadleaf flowering trees and shrubs; 2014. www.cmg.colostate.edu. Accessed 29 Mar 2016.

27. Botstein D, White R, Skolnick M, Davis R. Construction of a genetic map in man using restriction fragment length polymorphisms. Am J Hum Genet. 1980;32:314-31.

28. Mohajer S, Ashraf A, Taha MR, Syafawati Y, Saleh A. Genetic diversity analysis of agro-morphological and quality traits in populations of sainfoin (Onobrychis sativa). AJCS. 2013;7:1024-31.

29. Zisadza-Gandiwa P, Mabika CT, Kupika OL, Gandiwa E, Murungweni C. Vegetation structure and compositionacross different land uses in Semiarid Savana of Southern Zimbabwe. Int J Biodivers. 2013;2013:5.

30. Brodribb T, Feild T, Sack L. Viewing leaf structure and evolution from a hydraulic perspective. Funct Plant Biol. 2010;37:488-98.

31. Armbruster W, Muchhala N. Associations between floral specialization and species diversity: cause, effect, or correlation? Evol Ecol. 2009;23:159-79.

32. Adrienne B, Nicotra AH, Andrea L, Boyce C, Jones D, Niklas E, et al. The evolution and functional significance of leaf shape in the angiosperms. Funct Plant Biol. 2011;38:535-52.

33. Hejtmankova K, Kotikova Z, Hamouz K, Vladimir P, Josef V, Jaromir L. Influence of flesh colour, year and growing area on carotenoid and anthoyacanin content in potato tubers. J Food Compos Anal. 2013;32:20-37.

34. Hasnat Muhammad Solaiman A, Nishizawa T, Suvra Roy T, Rahman M, Chakraborty R, Choudhury J, et al. Yield, dry matter, specific gravity and color of three bangladeshi local potato cultivars as influenced by stage of maturity. J Plant Sci. 2015;10:108-15.

35. De Riek J, Calsyn E, Everaert I, Van Bockstaele E, de Loose M. AFLP based alternatives for the assessment of distinctness, uniformity and stability of sugar beet varieties. Theor Appl Genet. 2001;103:1254-65.

36. Pirkhezri MHME. Genetic diversity in different populations of Matricaria chamomilla L. growing in Southwest of Iran, based on morphological and RAPD markers. Res J Med Plant. 2010;4:1-13.

Ready to submit your research? Choose BMC and benefit from

- fast, convenient online submission

- thorough peer review by experienced researchers in your field

- rapid publication on acceptance

- support for research data, including large and complex data types

- gold Open Access which fosters wider collaboration and increased citations

- maximum visibility for your research: over $100 \mathrm{M}$ website views per year

At BMC, research is always in progress.

Learn more biomedcentral.com/submissions 